\title{
UJI AKTIVITAS ANTIOKSIDAN EKSTRAK ETANOL DAUN SELADA ROMAINE (Lactuca sativa var. Longifolia) DAN DAUN SELADA KERITING (Lactuca sativa var. Crispa) BESERTA IDENTIFIKASI BEBERAPA SENYAWA ANTIOKSIDAN
}

\author{
Maria Ulfah*, Ady Laksono Putro, Efa Erfiana Safitri
}

Fakultas Farmasi Universitas Wahid Hasyim

Jl. Menoreh Tengah X/22 Semarang (024)8505680

*Email: mariau_astra@yahoo.com

\section{INTISARI}

Radikal bebas diduga sebagai pemicu berbagai macam penyakit degeneratif. Antioksidan merupakan senyawa yang dapat menangkal radikal bebas. Penelitian ini bertujuan untuk mengetahui aktivitas antioksidan dengan metode DPPH dan menganalisis senyawa aktif yang terdapat dalam ekstrak selada romaine (Lactuca sativa var. Longifolia) dan ekstrak selada keriting (Lactuca sativa var. Crispa). Ekstraksi tanaman selada romaine dan tanaman selada keriting menggunakan metode maserasi dengan pelarut etanol $70 \%$. Konsentrasi ekstrak yang digunakan adalah 12,$5 ; 25 ; 50 ; 100 ; 200$ dan 400 ppm serta konsentrasi vitamin $\mathrm{C}$ sebagai pembanding adalah 0,$5 ; 1 ; 1,5 ; 2 ; 2,5$ dan 3 ppm diuji aktivitas antioksidannya dengan metode DPPH secara spektrofotometri visibel, hingga diperoleh nilai $\mathrm{IC}_{50}$. Identifikasi senyawa aktif dilakukan dengan skrining fitokimia dan Kromatografi Lapis Tipis (KLT). Hasil penelitian menunjukkan bahwa selada romaine memiliki nilai $\mathrm{IC}_{50}$ sebesar $151,1515 \mathrm{ppm}$ dan selada keriting sebesar 183,7560 ppm dan vitamin $C$ sebesar 1,7005 ppm. Senyawa kimia yang terkandung dalam ekstrak etanol selada romaine dan selada keriting adalah alkaloid, fenol dan flavonoid.

Kata kunci: Antioksidan, DPPH, $\mathrm{IC}_{50}$, KLT, Selada Romaine, Selada Keriting

\section{ABSTRACT}

Free radicals are suspected as triggers of various degenerative diseases. Antioxidants are compounds that can counteract free radicals. This study aims to determine the antioxidant activity by DPPH method and analyze the active compounds contained in romaine lettuce extract (Lactuca sativa var Longifolia) and lactuca sativa var Crishpa lettuce extract (Lactuca sativa var Crishpa). Romaine lettuce and and lactuca sativa var Crishpa was done extraction with a maceration method using 70\% as ethanol solvent. The concentration of extract used was 12.5; 25; 50; 100; 200 and 400 ppm and vitamin C concentrations as comparison was $0.5 ; 1 ; 1.5 ; 2 ; 2,5$ and 3 ppm tested its antioxidant activity by DPPH method by spectrophotometry visible, until IC $C_{50}$ value was obtained. The identification of the active compound was performed by phytochemical screening and Thin Layer Chromatography $(T L C)$. The results showed that romaine lettuce has $I C_{50}$ value of 151,1515 ppm and lactuca sativa var Crishpa has $I_{50}$ value of 183,7560 ppm and vitamin $C$ value was 1,7005 ppm. The chemical compounds contained in romaine ethanol extract and lactuca sativa var Crishpa lettuce extract are alkaloids, phenols and flavonoids.

Keywords: Antioxidant, DPPH, IC ${ }_{50}$, TLC, Romaine, Lactuca sativa var Crishpa 
*Corresponding author:

Maria Ulfah

Fakultas Farmasi Universitas Wahid Hasyim

Jl. Menoreh Tengah X/22 Semarang (024)8505680

\section{PENDAHULUAN}

Radikal bebas adalah suatu molekul yang memiliki elektron tidak berpasangan dalam orbital terluarnya sehingga sangat reaktif. Radikal bebas terbentuk di dalam tubuh dalam kondisi normal (Winarsi, 2007). Radikal bebas ini dapat diatasi dengan suatu senyawa penangkal yang disebut antioksidan. Sumber radikal bebas ada yang bersifat internal dari dalam tubuh dan bersifat eksternal dari luar tubuh (Khaira, 2010). Hal tersebut menyebabkan senyawa antioksidan alami sangat diharapkan dan dibutuhkan. Salah satu sumber antioksidan alami yang berasal dari tumbuhan dan dapat ditemui di Indonesia adalah selada keriting (Lactuca sativa var Crishpa) dan selada romaine (Lactuca sativa var Longivolia). Kandungan kimia tanaman selada keriting adalah betakaroten, falat, lutein, senyawa indol, karotenoid serta senyawa fitokimia seperti fenolik, antosianin dan asam fenolik (López dkk., 2014), (Backer dkk., 1968). Kandungan kimia tanaman Selada Romaine antara lain carotenoid, antosianin dan fenolik (Kim dkk., 2016). Selada keriting dan selada romaine sering dikonsumsi oleh masyarakat sebagai sayur dan lalapan makanan. Selain itu juga mempunyai manfaat yang baik bagi kesehatan tubuh, tetapi mengenai aktivitas sebagai antioksidan dan kandungan senyawa kimia di dalam tanaman selada keriting belum diketahui. Berdasarkan latar belakang di atas, perlu dilakukan penelitian untuk mengetahui aktivitas antioksidan ekstrak etanol selada keriting dan selada romaine serta untuk mengetahui beberapa kandungan senyawa antioksidan yang dapat dimanfaatkan dalam kehidupan sehari-hari.

\section{METODE PENELITIAN Bahan Penelitian}

Selada Romaine dan selada keriting, Etanol 70\% (PT. Brataco), aquadest p.a, kristal DPPH (2,2-Difenil-1-Pikrilhidrazil), vitamin $\mathrm{C}$, silika gel $60 \mathrm{~F}_{254}$. Kloroform, metanol etil asetat, air dan butanol, asam asetat, Dragendorff, $\mathrm{FeCl}_{3}$ dan uap amoniak.

\section{Alat Penelitian}

Timbangan elektrik (Henherr), oven (Memmert), blender (Philiph), ayakan Mesh 40, tampah, moisture balance (Ohaus), seperangkat toples maserasi, rotary evaporator (Heidolp) dan alat-alat gelas (Pyrex), kayu pengaduk dan seperangkat alat saring vacum. Kaca bejana dan Lampu sinar UV.

\section{Jalannya Penelitian}

\section{Pembuatan ekstrak etanol daun selada romaine dan daun selada keriting}

Daun selada romaine dan daun selada keriting yang telah dipanen disortasi basah, selanjutnya dicuci bersih dengan air kemudian ditiriskan dan diangin-anginkan. Setelah itu dikeringkan dengan oven pada suhu $50-70^{\circ} \mathrm{C}$ sampai kering. Simplisia kering ditimbang dan dibuat serbuk dengan cara diblender kemudian diayak dengan ayakan ukuran 40 mesh serta diukur kadar airnya dengan moisture balance. Serbuk simplisia daun selada romaine dan daun selada kriting diekstraksi dengan cara maserasi menggunakan cairan penyari etanol $70 \%$ yang dibiarkan selama tiga hari dalam toples kaca tertutup rapat dan terhindar dari cahaya dengan pengadukan minimal 3 kali sehari dan kemudian disaring sehingga diperoleh maserat I. Ampas setelah tiga hari kemudian diperas dan ditambahkan sisa 25\% cairan penyari etanol. Maserat I dan II dicampur dan dienaptuangkan selama dua hari untuk selanjutnya dipekatkan dengan rotary evaporator pada suhu $<50^{\circ} \mathrm{C}$ sampai diperoleh ekstrak kental.

\section{Uji aktivitas antioksidan ekstrak etanol selada romaine dan ekstrak etanol selada keriting dengan metode DPPH}

Ekstrak etanol daun selada romaine dan ekstrak etanol daun selada keriting dibuat dalam seri konsentrasi $(12,5 ; 25 ; 50 ; 100 ; 200$ dan 400) ppm. Seri konsentrasi vitamin C $(0,5 ; 1,0 ; 1,5 ; 2,0 ; 2,5$ dan 3,0) ppm digunakan sebagai larutan antioksidan standar. Sebanyak 2,0 mL larutan DPPH 0,1 
$\mathrm{mM}$ ditambahkan dengan 1,0 $\mathrm{mL}$ larutan sampel, kemudian divortex, lalu didiamkan dalam tempat gelap selama 30 menit. Absorbansi larutan DPPH 0,1 mM dibaca dengan menggunakan spektrofotometer UV-Vis pada panjang gelombang $516,6 \mathrm{~nm}$. Perbandingan absorbansi sampel dan absorbansi larutan kontrol digunakan dalam perhitungan persentase aktivitas antioksidan ekstrak etanol daun selada romaine dan selada keriting atau vitamin C terhadap terhadap radikal bebas DPPH.

\section{Uji identifikasi senyawa kimia}

\section{a. Senyawa alkaloid}

Bahan Identifikasi kandungan senyawa alkaloid dalam ekstrak etanol daun selada romaine dan ekstrak etanol daun selada kriting dilakukan dengan melarutkan ekstrak dengan etanol p.a, kemudian sampel ditetesi pereaksi dragendorff. Identifikasi senyawa alkaloid menggunakan metode KLT dilakukan dengan lempeng silica gel (fase diam) dan fase gerak kloroform : metanol (3:2).

\section{b. Senyawa fenolik}

Identifikasi kandungan senyawa fenolik dalam ekstrak etanol daun selada romaine dan selada keriting dilakukan dengan melarutkan sedikit ekstrak dengan etanol, kemudian ditetesi dengan $\mathrm{FeCl}_{3}$. Identifikasi senyawa fenolik menggunakan metode KLT dilakukan dengan fase diam lempeng silika gel dan fase gerak etil asetat : metanol : air (7:2:1).

\section{c. Senyawa flavonoid}

Identifikasi kandungan senyawa flavonoid dilakukan dengan cara melarutkan ekstrak etanol daun selada kriting dalam etanol, kemudian ditambahkan 0,05 mg serbuk magnesium, dan asam klorida tetes demi tetes, kocok kuat-kuat. Identifikasi senyawa flavonoid menggunakan KLT dilakukan dengan fase diam lempeng silika gel dan fase gerak butanol : asam asetat : air (7:1:2) (Harborne, 1996).

\section{Analisis Data}

Data uji aktivitas antioksidan yang dihasilkan berupa nilai absorbansi DPPH terhadap ekstrak etanol daun selada Romaine dan ekstrak etanol daun selada keriting dan baku pembanding vitamin $\mathrm{C}$, kemudian dihitung presentase aktivitas antioksidannya.

\section{HASIL PENELITIAN DAN PEMBAHASAN}

Hasil penelitian antioksidan ekstrak etanol daun selada romaine dan ekstrak etanol daun selada keriting dapat dilihat pada Tabel I.

\begin{tabular}{cccccc} 
Tabel I. Hasil Uji Aktivitas Antioksidan Ekstrak Etanol Daun Selada Kriting dan Romaine \\
\hline Sampel & $\begin{array}{c}\text { Konsentrasi } \\
\text { sampel (ppm) }\end{array}$ & Absorbansi & $\begin{array}{c}\text { Aktivitas } \\
\text { antioksidan (\%) }\end{array}$ & $\begin{array}{c}\text { Persamaan } \\
\text { Regresi Linier }\end{array}$ & IC $_{\mathbf{5 0}}(\mathbf{p p m})$ \\
\hline Ekstrak & 12,5 & 0,631 & 29,2600 & Y=0,1033X+ & 183,75 \\
etanol & 25 & 0,607 & 31,9506 & 31,0180 & \\
selada & 50 & 0,556 & 37,6681 & & \\
kriting & 100 & 0,487 & 45,4035 & & \\
& 200 & 0,428 & 52,0179 & & \\
\hline & 400 & 0,257 & 71,1883 & & \\
Ekstrak & 12,5 & 0,623 & 30,1569 & $\mathrm{Y}=0,1148 \mathrm{X}+$ & 151,15 \\
etanol & 25 & 0,58 & 34,9775 & 32,6478 & \\
selada & 50 & 0,559 & 37,3318 & & \\
romaine & 100 & 0,48 & 46,1883 & & \\
& 200 & 0,33 & 63,0044 & & \\
\hline & 400 & 0,226 & 74,6636 & & \\
Vitamin C & 0,5 & 0,659 & 26,1210 & $\mathrm{Y}=23,2878 \mathrm{X}$ & \\
& 1 & 0,604 & 32,2869 & $+9,1168$ & \\
& 1,5 & 0,528 & 40,8071 & & \\
& 2 & 0,398 & 55,3811 & & \\
\hline
\end{tabular}


Hasil uji aktivitas antioksidan ekstrak etanol daun selada kriting dan romaine pada tabel I, menunjukkan bahwa semakin tinggi konsentrasi sampel yang digunakan maka semakin besar presentse aktivitas antioksidannya. Hal tersebut dikarenakan kemampuan senyawa antioksidan untuk merendam radikal bebas pada konsentrasi sampel yang tinggi semakin besar, sedangkan absorbansi yang dihasilkan semakin turun karena konsentrasi DPPH yang ada didalam sampel semakin kecil (Winarsi, 2007) serta mempunyai aktivitas antioksidannya tinggi dan sangat kuat dengan nilai $\mathrm{IC}_{50}$ sebesar 2,857 ppm ((Indranila dan Ulfah, 2015). Hasil dari nilai $\mathrm{IC}_{50}$ vitamin $\mathrm{C}$ dan esktrak etanol selada kriting tersebut, persamaan regresi linier memiliki koefisien korelasi yang mendekati 1 yang berarti adanya korelasi yang sangat kuat (Sarwono, 2006). Nilai koefisien korelasi terbaik untuk vitamin $\mathrm{C}$ yaitu 0,9786 serta nilai koefisien korelasi terbaik dari ekstrak etanol selada kriting sebesar 0,9865 . Hasil nilai $\mathrm{IC}_{50}$ vitamin $\mathrm{C}$ adalah $1,7005 \mathrm{ppm}$ serta hasil nilai $\mathrm{IC}_{50}$ ekstrak etanol selada kriting adalah $183,75 \mathrm{ppm}$. Semakin kecil nilai $\mathrm{IC}_{50}$ maka semakin kuat pula aktivitas antioksidan senyawa tersebut karena dengan konsentrasi yang kecil mampu menimbulkan efek. Penelitian ini menunjukan nilai $\mathrm{IC}_{50}$ ekstrak etanol selada keriting sebesar $183,75 \mathrm{ppm}$. Artinya, pada konsentrasi tersebut larutan uji dapat meredam DPPH sebesar 50\%. Menurut Bloiss (1958) aktivitas antioksidan dari ekstrak etanol selada kriting tersebut dikategorikan lemah karena memiliki $\mathrm{IC}_{50}$ berada diantara 151-200 ppm.

Hasil skrining fitokimia dapat dilihat pada Tabel II serta hasil kromatogram lapis tipis dapat dilihat pada Gambar 1 sampai 6.

Tabel II. Hasil Skrining Fitokimia ekstrak etanol daun selada kriting dan romaine

\begin{tabular}{|c|c|c|c|c|c|}
\hline Senyawa & Pereaksi & Tanda positif & Selada romaine & Selada Kriting & Kesimpulan \\
\hline \multirow[t]{2}{*}{ Alkaloid } & - Dragendorf & $\begin{array}{l}\text { - Adanya } \\
\text { endapan orange } \\
\text { / merah }\end{array}$ & $\begin{array}{l}\text { - Adanya endapan } \\
\text { orange }\end{array}$ & $\begin{array}{l}\text { - Adanya } \\
\text { endapan } \\
\text { orange }\end{array}$ & - Positif \\
\hline & - Mayer & $\begin{array}{l}\text { - Adanya } \\
\text { endapan putih / } \\
\text { kuning }\end{array}$ & $\begin{array}{l}\text { - Adanya endapan } \\
\text { putih }\end{array}$ & $\begin{array}{l}\text { - Adanya } \\
\text { endapan putih }\end{array}$ & - Positif \\
\hline Flavonoid & 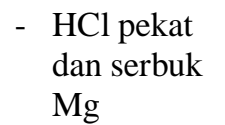 & $\begin{array}{l}\text { - Terbentuknya } \\
\text { warna merah/ } \\
\text { jingga }\end{array}$ & $\begin{array}{c}\text { - Terbentuknya } \\
\text { warna jingga }\end{array}$ & $\begin{array}{l}\text { - Terbentuknya } \\
\text { warna jingga }\end{array}$ & - Positif \\
\hline Fenol & - $\mathrm{FeCl}_{3}$ & $\begin{array}{l}\text { - Terbentuknya } \\
\text { warna hijau } \\
\text { gelap/ biru }\end{array}$ & $\begin{array}{l}\text { - Terbentuknya } \\
\text { warna hijau } \\
\text { gelap }\end{array}$ & $\begin{array}{l}\text { - Terbentuknya } \\
\text { warna hijau } \\
\text { gelap }\end{array}$ & - Positif \\
\hline
\end{tabular}

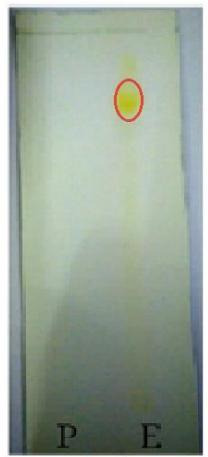

(a)

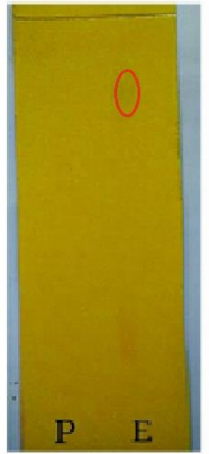

(b)

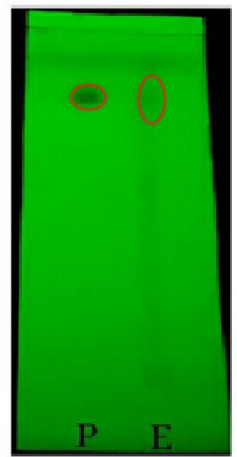

(c)

Gambar 1. Profil senyawa alkaloid dengan KLT, (p) pembanding (kafein), (e) sampel ekstrak selada Romaine, (a) sebelum disemprot Dragendorff, (b) setelah disemprot Dragendorff, (c) diamati pada sinar UV $254 \mathrm{~nm}$. 


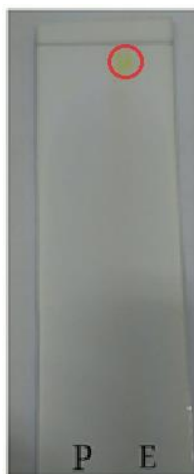

(a)

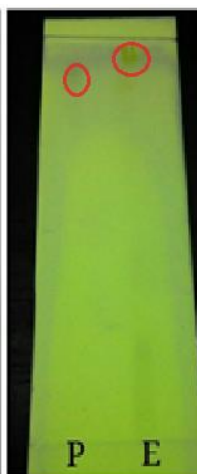

(b)

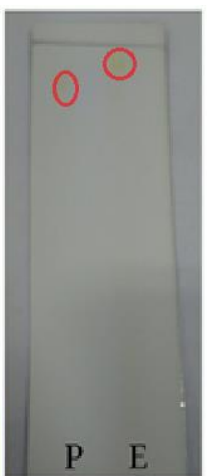

(c)

Gambar 2. Profil senyawa Flavonoid dengan KLT, (p) pembanding (kuersetin), (e) sampel ekstrak selada Romaine, (a) sebelum diuapi amoniak, (b) setelah diuapi amoniak (c) diamati pada sinar UV $254 \mathrm{~nm}$.

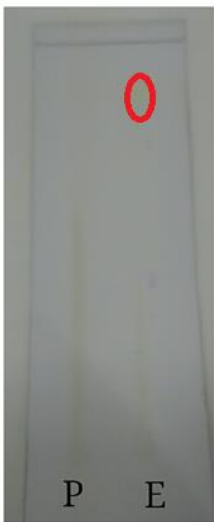

(a)

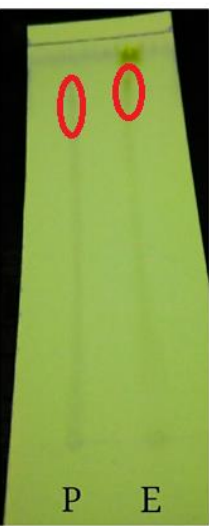

(b)

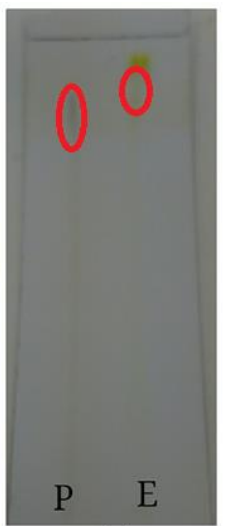

(c)

Gambar 3. Profil senyawa Fenolik dengan KLT, (p) pembanding (Tanin), (e) sampel ekstrak selada Romaine, (a) sebelum disemprot $\mathrm{FeCl}_{3}$; (b) diamati pada sinar UV 254 nm; setelah disemprot $\mathrm{FeCl}_{3}$,

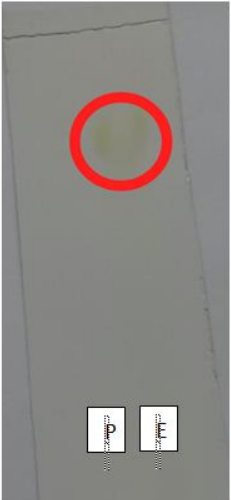

3 (a)

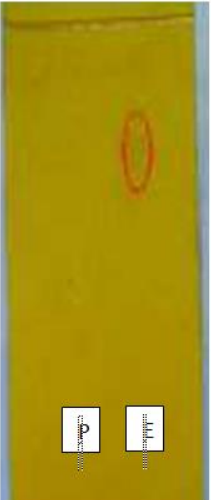

(b)

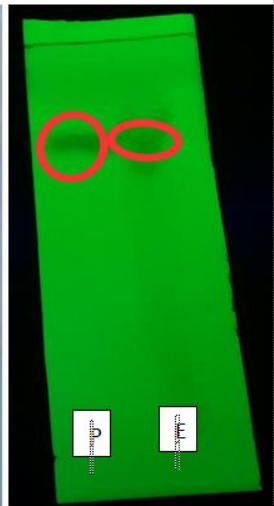

(c)l

Gambar 4. Profil senyawa alkaloid dengan KLT, (p) pembanding (kafein), (e) sampel ekstrak selada keriting, (a) sebelum disemprot Dragendorff, (b) setelah disemprot Dragendorff, (c) diamati pada sinar UV $254 \mathrm{~nm}$. 


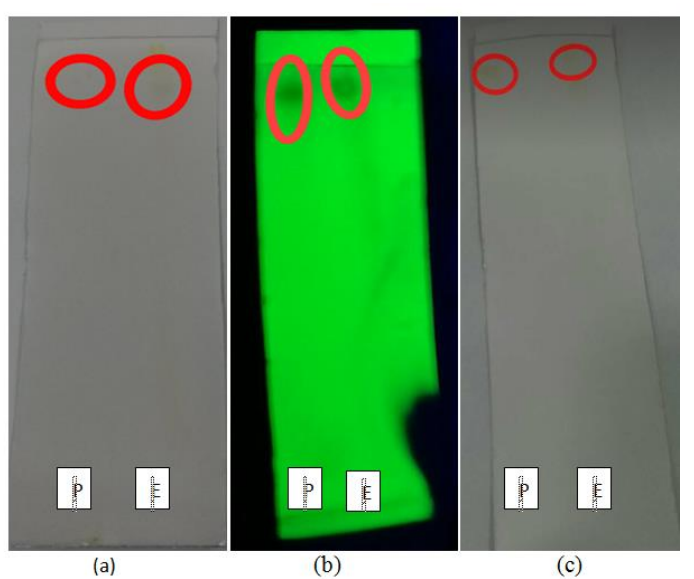

Gambar 5. Profil senyawa Flavonoid dengan KLT, (p) pembanding (kuersetin), (e) sampel ekstrak selada keriting, (a) sebelum diuapi amoniak, (b) setelah diuapi amoniak (c) diamati pada sinar UV $254 \mathrm{~nm}$.

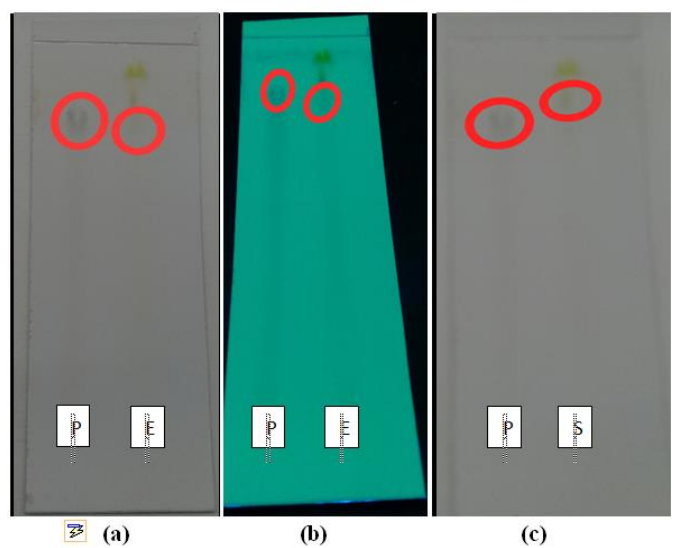

Gambar 6. Propil senyawa Fenolik dengan KLT, (p) pembanding (Tanin), (e) sampel ekstrak selada keriting, (a) sebelum disemprot $\mathrm{FeCl}_{3}$; (b) diamati pada sinar $\mathrm{UV} 254$ nm; setelah disemprot $\mathrm{FeCl}_{3}$,

Tabel II dan gambar KLT menunjukan bahwa skrining fitokimia beberapa senyawa yang teridentifikasi adalah senyawa alkaloid, flavonoid dan fenolik dalam ekstrak etanol daun selada keriting dan romaine. Adanya kandungan senyawa alkaloid ditunjukkan dengan terbentuknya spot atau endapan berwarna merah hingga jingga dan senyawa fenolik ditunjukkan dengan terjadinya perubahan warna spot dan larutan menjadi hijau, biru, merah, ungu dan hitam dan flavonoid ditunjukkan dengan terbentuknya sopt atau warna larutan merah, kuning atau jingga (Harborne, 1996).

\section{KESIMPULAN}

Ekstrak etanol daun selada keriting mempunyai aktivitas antioksidan dengan metode DPPH. Nilai Inhibition Concentration $\left(\mathrm{IC}_{50}\right.$ ) yang diperoleh dari ekstrak etanol daun selada kriting adalah sebesar 183,75 ppm dan Vitamin C sebesar 1,7005 ppm. Senyawa aktif yang terkandung di dalam ekstrak etanol daun selada keriting dan romaine adalah alkaloid, flavonoid dan fenolik.

\section{SARAN}

Perlu dilakukan penelitian aktivitas antioksidan terhadap ekstrak etanol daun selada keriting dengan menggunakan metode ekstraksi yang lain dan perlu dilakukan fraksinansi ekstrak etanol daun selada keriting. 


\section{DAFTAR PUSTAKA}

Backer, C.A., 1968, Flora of Java Spermatophytes Only Vol. II, Groningen, Noordhoft-The Netherlands, Pp. 476-477.

Blois, M.S., 1958, Antioxidant Determiination by The Use Of A Stable Free Radical, Nature, 181: 1199-1200.

Harborne, J.B, 1996, Metode Fitokimia, Edisi Kedua, Penerbit ITB, Bandung.

Indranila dan Ulfah, M., 2015, Uji Aktivitas Antioksidan Ekstrak Etanol Daun Karika (Carica Pubescens) Dengan Metode DPPH Beserta Identifikasi Senyawa Alkaloid, Fenol Dan Flavonoid, Prosiding Seminar Nasional Peluang Herbal Sebagai Alternatif Medicine.

Khaira, K., 2010, Menangkal Radikal Bebas dengan Antioksidan, Jurnal Sainstek Vol. II, No. 2: 183-187, ISSN: 2085-8019.

Kim H. J., et all, 2016, Nutritional Value Of Crips Head And Romaine Lettuces (Latuca Sativa L.), Journal of Agricultural Science.

López, A., Javier, G. A., Fenoll, J., Hellin, P., \& Flores, P., 2014, Chemical Composition And Antioxidant Capacity Of Lettuce: Comparative Study Of Regular-Sized (Romaine) And Baby-Sized (Little Gem And Mini Romaine) Types. Journal Of Food Composition And Analysis, 33(1), 39-48.

Sarwono, J., 2006, Metode Penelitian Kuantitatif dan Kualitatif, Graha Ilmu, Yogyakarta.

Winarsi, H, 2007, Antioksidan Alami Dan Radikal Bebas , Penerbit Kanisius, Yokyakarta 